\section{Assessment of the initiation and tolerability of tapentadol prolonged-release therapeutics in patients with chronic pain in a chronic pain unit setting in Portugal: a cross-sectional study} Caracterización de la introducción y tolerabilidad del tapentadol de liberación prolongada en pacientes con dolor crónico en una unidad del dolor en Portugal: estudio transversal

Duque, M. MD¹; do Céu Loureiro, M. MD²; Vico, M. MD, MSc, PhD, MBA 2,3

${ }^{1}$ Vila Nova de Gaia/Espinho Hospital Centre

${ }^{2}$ Tondela-Viseu Hospital Centre - CACB (Clinical Academic Center of Beiras). Portugal

${ }^{3}$ Faculty of Health Sciences. University of Beira Interior. Portugal

\section{Resumen}

Introducción. El tapentadol de liberación prolongada (LP) es un analgésico de acción central indicado para el tratamiento del dolor moderado a intenso. El objetivo de este estudio es caracterizar la introducción y la tolerabilidad del tapentadol LP en pacientes seguidos en una unidad de dolor crónico mediante la evaluación de la prevalencia de eventos adversos y las principales razones para la interrupción del tratamiento o la reducción de la dosis.

Material y métodos. En este estudio transversal, todos los pacientes seguidos en la unidad de dolor crónico bajo tratamiento con tapentadol LP fueron analizados durante un período de 8 meses. Las características demográficas y clínicas de los pacientes fueron recolectadas retrospectivamente a través de la consulta de los archivos clínicos.

Resultados. De los 127 pacientes incluidos en el estudio, $119(93,7 \%)$ reemplazaron analgésicos opioides por tapentadol LP, siendo este el fármaco de primera línea en $8(6,3 \%)$ pacientes. Durante el estudio, 26 $(20,5 \%)$ pacientes interrumpieron el tratamiento con tapentadol LP y $5(3,9 \%)$ pacientes redujeron su dosis. Las principales razones para la interrupción de tapentadol LP fueron eventos adversos: náuseas o vómitos (32.1\%), estreñimiento (19.2\%), mareos $(19.2 \%)$ y ausencia del efecto analgésico deseado. Discusión. La prevalencia de la interrupción del tratamiento con tapentadol LP y los eventos adversos asociados con su uso fue similar a la descrita anteriormente. Se necesitarán más estudios para optimizar el tratamiento de pacientes con dolor crónico tapentadol LP en el contexto de unidades de dolor crónico.

Conclusión. En nuestro estudio, los pacientes que suspendieron el tapentadol corresponden a un porcentaje bajo. Encontramos que el motivo más frecuente fueron los efectos adversos gastrointestinales, seguidos por la falta de efecto analgésico y mareos. El tapentadol PR parece ser un fármaco bien tolerado por los pacientes seguidos en la unidad del dolor.

\section{Abstract}

Introduction. Tapentadol prolonged-release (PR) is a centrally acting oral analgesic prescribed for the treatment of moderate to severe pain. This study aimed to characterize the introduction and tolerability of tapentadol PR treatment in patients with chronic pain who were attending a hospital-based chronic pain outpatient unit, by assessing the prevalence and main reasons for treatment discontinuation or dose reduction.

Material and Methods. In this cross-sectional observational study, all patients visiting an outpatient chronic pain unit who were taking tapentadol PR as their analgesic therapy were included. Demographic and clinical data of patients, and reasons for tapentadol PR treatment discontinuation or reduction during an eight-month period were extracted from the medical records.

Results. Of the 127 enrolled patients, 119 (93.7\%) were switched from opioids to tapentadol PR and $8(6.3 \%)$ were taking tapentadol PR as their primary medication for the treatment of chronic pain. During the study, 26
Palabras clave: Analgésicos Opioides; Dolor Crónico; Analgesia; Efectos Secundarios y Reacciones Adversas; Tapentadol.
ACTUALIDAD M É D I C A www.actualidadmedica.es (C)2020.Actual.Med. Todoslos derechosreservados
Manuel Vico, MD, MSc, PhD, MBA. Serviço de Anestesiologia, Centro Hospitalar Tondela Viseu Avenida Rei D. Duarte, 3504-509, Viseu, Portugal E-Mail: mvico@fcsaude.ubi.pt 
(20.5\%) patients discontinued tapentadol PR treatment and 5 (3.9\%) patients reduced their dose. The most frequently reported reasons for tapendadol PR discontinuation were adverse reactions - nausea or vomiting (32.1\%), constipation (19.2\%), dizziness (19.2\%) - and lack of analgesic effect $(30.8 \%)$

Discussion. Prevalence of treatment discontinuation and adverse reactions associated with the use of tapentadol PR are similar to the ones previously reported. Further studies are needed to improve the management of chronic pain patients with tapentadol PR in an outpatient setting.

Conclusion. Patients with chronic pain in our study discontinued their tapentadol PR treatment at a low percentage. We found that the most frequent reason for discontinuation of tapentadol PR was gastrointestinal disorders, followed by lack of analgesic effect, and dizziness. Tapentadol PR appears to be a well-tolerated for the control of chronic pain in patients attending an outpatient unit.

Funding: Grunenthal S.A. contributed with a grant to support Scientific Toolbox Consulting regarding medical writing services.

\section{INTRODUCTION}

Chronic pain was defined as persistent or recurrent pain lasting longer than 3 months. Its incidence and frequency increase with age, number of comorbidities, as well as the number of medications. ${ }^{1}$ The pain is usually nociceptive, neuropathic or a mixture of the two. ${ }^{8}$ Opioid analgesics are recommended by the World Health Organization analgesic ladder for the treatment of moderateto-severe pain. ${ }^{2}$ Their main mechanism of analgesic action is the $\mu$-opioid receptor agonism. ${ }^{3}$ However, the use of opioid analgesics has adverse reactions difficult to control such as nausea, vomiting, and constipation and are also associated with phenomena of analgesic tolerance and drug dependence. ${ }^{3}$ These factors may contribute to the abandonment of opioid analgesics therapeutics. For these reasons, achieving and maintaining the balance between analgesia and safety difficult. ${ }^{9}$

Tapentadol hydrochloride is a centrally acting analgesic indicated for the treatment of chronic severe pain that acts in two ways: through the agonism of $\mu$-opioid receptors, attenuating the upward transmission in the pain pathway; and by inhibiting the reuptake of norepinephrine, leaving more free norepinephrine in the downward pain pathway which allows modulation of the painful stimulus. ${ }^{3-5}$

The $\mu$-opioid receptor binding affinity of the drug was considerably lower that of morphine in vitro, although its analgesic potency in animal models was only two- or threetimes lower than that of morphine, highlighting the contribution of noradrenaline reuptake inhibitor activity to its analgesic effect. ${ }^{9}$ The dual mechanism of action of tapentadol and its prolonged-release (PR) formulation reduces the intakes per day and allows for fewer drug side effects than equianalgesic doses of opioids. ${ }^{3,5,7}$ This might increase the therapeutic compliance in treating chronic pain of diverse etiologies. ${ }^{3,4}$ This simplification of the therapeutic approach increases the patient's adherence and compliance to the therapy. While tapentadol is a weak $\mu$-opioid agonist, its use has several benefits: less opioid side-effects with equipotent analgesia, ${ }^{3,4}$ does not have active metabolites, does not induce hepatic cytochromes, nor has important binding to proteins. ${ }^{3}$ In addition, tapentadol PR low risk for intolerance and its low incidence of adverse reactions allows a faster dose titration, and hence, a faster and more effective pain control. ${ }^{7}$

This study aimed to characterize the introduction and tolerability of tapentadol PR therapeutics in patients with chronic pain, who attended a hospital-based outpatient unit for chronic pain over a period of 8 months, by assessing the prevalence of treatment discontinuation and dose reduction, the main reasons for tapentadol $P R$ discontinuation, and the time to treatment discontinuation for each of the main reasons.

\section{MATERIALS AND METHODS}

In this cross-sectional observational study, we examined the medical records of outpatients who attended the Chronic Pain Unit in an eight-month period following the introduction of tapentadol PR therapeutics. Consecutive patients previously diagnosed with chronic pain (i.e., pain that persists beyond the usual course of an acute disease or after a reasonable time for healing to occur; this healing period typically can vary from 1 to 6 months) ${ }^{6}$ were included in the study. Inclusion criteria were: being 18 years old or older, and having at least one prescription for tapentadol PR. Patients were excluded if they had missing data regarding dates of initiation and/or discontinuation of tapentadol LR therapeutics, or died.

Collected demographic and medical variables were age, gender, and etiology of chronic pain (i.e. oncologic or non-oncologic). Data collection regarding the analgesic therapeutics included maximum daily dose and duration of tapentadol LR therapeutics, and existence of concomitant analgesic medication. The outcome measures for tolerability of tapentadol LR were: treatment discontinuation (stopping the use of tapentadol LR); dose reduction of tapentadol LR; main reasons for the discontinuation or dose reduction of tapentadol PR therapeutics (e.g., lack of analgesic effect, reduction of analgesic need, or intolerability because of adverse reactions such as gastrointestinal, nervous system, skin or general disorders); and time to treatment discontinuation for each of main reasons. Categorical data were summarized as number (percentage) and continuous data as mean \pm standard deviation (minimum-maximum) or median (minimummaximum). The statistical software SPSS version 22.0 for Windows (SPSS, Chicago, IL) was used to analyze the data.

This study conformed with the principles outlined in the Helsinki Declaration and was approved by the Ethics Committee of Centro Hospitalar Tondela-Viseu.

\section{RESULTS}

Out of 135 patients who were attending the outpatient unit and have been treated with tapentadol PR for chronic pain between March and November 2014, 8 patients were excluded. Seven patients were excluded because of incomplete data, and one patient died. The demographic characteristics of the 127 patients included in our study were: mean age of $63.0 \pm 13.6$ (32-91) years old, and mostly female $(72.4 \%, n=92)$. The most common cause of chronic pain was non-oncologic $(84.3 \%, \mathrm{n}=107)$. At study entry, most patients had switched from opioids to tapentadol PR and maintained concomitant analgesic medications $(93.7 \%, n=119)$, whereas 8 patients were taking tapentadol PR as the firstchoice medication for the treatment of chronic pain. The 
starting dose of tapentadol PR used was twice-daily $50 \mathrm{mg}$ in most patients with titration to effective analgesic dose. The mean maximum daily dose of tapentadol PR for all patients was $172.4 \pm 91.2(100-400) \mathrm{mg} /$ day in two divided doses.

Table 1 shows the prevalence and characteristics of chronic pain patients who discontinued, reduced the dose, or continued the treatment with tapentadol PR. At eight months, the prevalence of all-cause treatment discontinuation and dose reduction of tapentadol PR was 20.5\% $(n=26)$ and 3.9\% $(n=5)$, respectively. All 31 patients who discontinued or reduced the dose of tapentadol PR used concomitant analgesic medication (e.g., paracetamol, anti-inflammatory drugs, antiepileptic drugs, antidepressants), and most of these patients were being treated for non-oncologic chronic pain $(n=28)$. Overall, the main reasons for treatment discontinuation were adverse reactions $(16.5 \%, \mathrm{n}=21)$, lack of analgesic effect $(6.3 \%, n=8)$, or reduction of analgesic needs $(0.8 \%, n=1)$.
The reasons that led to treatment discontinuation or dose reduction of tapentadol PR are summarized in Table 2. During the study period, $53.8 \%(n=14)$ of patients who discontinued tapentadol PR reported gastrointestinal disorders, which included nausea or vomiting $(n=6)$, constipation $(n=4)$, diarrhea $(n=2)$, and gastric discomfort $(n=2)$; and $30.8 \%(n=$ 8 ) of patients reported lack of analgesic effect.

Other reasons that led to discontinuation of tapentadol PR treatment were dizziness $(n=5)$, legs edema $(n=2)$, reduction of analgesic needs because of reduction in patients' pain severity $(n=1)$, among others (e.g., urinary incontinence, pruritus, feeling hot, lethargy, headache, dyspnea).

On the other hand, reported main reasons leading to dose reduction of tapentadol PR were: constipation $(n=1)$, reduction of analgesic needs $(n=1)$, dyspnea $(n=1)$, and confusion $(\mathrm{n}=1)$.

\begin{tabular}{|l|l|l|l|}
\hline \multicolumn{2}{|l|}{ Tapentadol PR treatment $(n=127)$} \\
\hline Characteristic & Discontinuation & Dose reduction & Continuation \\
\hline No. of patients (\%) & $26(20.5)$ & $5(3.9)$ & $96(75.6)$ \\
\hline Female, $n(\%)$ & $20(15.7)$ & $4(3.1)$ & $68(53.5)$ \\
\hline Etiology of chronic pain, $\mathrm{n}(\%)$ & & & $17(13.4)$ \\
\hline Oncologic & $3(2.4)$ & $0(0.0)$ & $79(62.2)$ \\
\hline Non oncologic & $23(18.1)$ & $5(3.9)$ & $8(6.3)$ \\
\hline Analgesic medication, $\mathrm{n}(\%)$ & & & $88(69.3)$ \\
\hline Tapentadol PR alone & $0(0.0)$ & $5(0.0)$ & $(3.9)$ \\
\hline Tapentadol PR with concomitant analgesic drugs & $26(20.5)$ & & \\
\hline
\end{tabular}

Table 1. Demographic and clinical characteristics of patients with chronic pain who discontinued, reduced the dose, or continued the tapentadol prolonged-release (PR) treatment.

\begin{tabular}{|c|c|c|}
\hline \multirow[b]{2}{*}{ Event } & \multicolumn{2}{|l|}{ Tapentadol PR treatment } \\
\hline & Discontinuation $(n=26)$ & Dose reduction $(n=5)$ \\
\hline Adverse reaction, n (\%) & $21(80.8)$ & $1(24.2)$ \\
\hline Gastrointestinal disorders & $14(53.8)$ & $1(24.2)$ \\
\hline Nausea/vomiting & $6(23.1)$ & \\
\hline Constipation & $4(15.4)$ & $1(24.2)$ \\
\hline Diarrhea & $2(7.7)$ & \\
\hline Gastric discomfort & $2(7.7)$ & \\
\hline Dizziness & $5(19.2)$ & - \\
\hline Legs edema & $2(7.7)$ & - \\
\hline Lack of analgesic effect, $n$ (\%) & $8(30.8)$ & \\
\hline Reduction of analgesic needs, $\mathrm{n}(\%)$ & $1(3.8)$ & $1(24.2)$ \\
\hline Other/unknown, n (\%) & $7(26.9)$ & $2(40.0)$ \\
\hline
\end{tabular}

Table 2. Reasons for discontinuation or dose reduction of tapentadol prolonged-release $(P R)$ treatment in patients with chronic pain. 
Mean time to treatment discontinuation with tapentadol PR for all patients was $42.4 \pm 41.2(1-120)$ days $(n=26)$. Six patients withdrew during the first week of tapentadol PR therapeutics, because of nausea, constipation, or dizziness, whereas 4 patients tolerated longest treatment periods of 110 to 120 days before discontinuation. These patients reported lack of analgesic effects as the main reason for discontinuation and resumed their previous opioid therapy.

Table 3 shows the duration and median maximum daily dose of tapentadol PR treatment for the most common reasons for discontinuation. Gastrointestinal disorders led to tapentadol PR discontinuation after average of $25.8 \pm 27.6$ days of treatment $(n=14)$, dizziness led to discontinuation after an average of 23.4 \pm 36.8 days $(n=5)$, and lack of analgesic effects led to discontinuation after an average of $62.0 \pm 49.1$ days of treatment $(n=8)$.

\section{FUNDING}

Grünenthal S.A. contributed with a grant to support Scientific Toolbox Consulting regarding medical writing services.

\section{CONFLICT OF INTEREST}

Manuel Vico has received fees from Grünenthal for advice on chronic pain and for lectures at courses of chronic pain.

Mélanie Duque and Maria do Céu Loureiro have no conflict of interest to declare.

\begin{tabular}{|l|l|l|l|}
\hline Treatment & $\begin{array}{l}\text { Gastrointestinal disorders } \\
(\mathrm{n}=14)\end{array}$ & $\begin{array}{l}\text { Dizziness } \\
(\mathrm{n}=5)\end{array}$ & $\begin{array}{l}\text { Lack of analgesic effect } \\
(\mathrm{n}=8)\end{array}$ \\
\hline $\begin{array}{l}\text { Time to discontinuation, mean } \pm \text { SD } \\
\text { (min-max), days }\end{array}$ & $25.8 \pm 27.6(1-89)$ & $23.4 \pm 36.8(1-87)$ & $62.0 \pm 49.1(11-120)$ \\
\hline $\begin{array}{l}\text { Maximum daily dose, median } \\
\text { (min-max), mg }\end{array}$ & $100(100-200)$ & $100(100-200)$ & $200(100-400)$ \\
\hline
\end{tabular}

Table 3. Duration and daily dose of tapentadol prolonged-release treatment before discontinuation owing to the most frequent adverse effects in patients with chronic pain.

\section{DISCUSSION}

This was the first study that investigated the introduction and tolerability of tapentadol PR for chronic pain treatment in outpatients attending a chronic pain unit in Portugal. In these patients, maximum daily dose of tapentadol PR ranged from 100 to $400 \mathrm{mg} /$ day and duration of treatment was 1 to 120 days. Prevalence of all-cause treatment discontinuation and dose reduction for tapentadol PR was $20.5 \%$ and $3.9 \%$, respectively. These were primarily due to adverse reactions and lack of analgesic effect.

Tapentadol PR use for up to 2 years has been reported to be generally well tolerated in the clinical trials, pooled analyses and clinical practice studies. ${ }^{9}$

In our study, we found that the prevalence of tapentadol PR discontinuation owing to adverse reactions is $16.5 \%$, which was similar to those of other studies about the tolerability of tapentadol in pain therapeutics (13-22\%). ${ }^{3,4}$ Moreover, we show that the most frequent adverse effects associated with the use of tapentadol PR reported in our unit - nausea, vomiting, constipation, dizziness - are similar to the ones described in previous studies, being these less frequent than those of other opioids. ${ }^{3-5}$ We also found other commonly described reasons for discontinuation (i.e., pruritus, feeling hot, and lethargy), ${ }^{3}$ as well as less frequently reported adverse reactions (i.e., legs edema, urinary incontinence, and dyspnea).

Several limitations may be presented for our study. We included in our study all patients that were available to us from a single unit, and no sample size calculation was carried out. Therefore, results from our study may not necessarily be generalized to other settings, or for patients with different clinical backgrounds. For instance, further studies with tapentadol PR should include more representative subsamples of patients with different etiologies for chronic pain.

In conclusion, we found that the most frequent reason for discontinuation of tapentadol PR was gastrointestinal disorders, followed by lack of analgesic effect, and dizziness. Patients discontinued their tapentadol PR treatment at a non-negligible percentage, but, in most of the cases, this medication was well-tolerated by these patients in an outpatient chronic pain unit setting.

\section{REFERENCIAS BIBLIOGRÁFICAS}

1. Zampi M. Efficacy and tolerabylity of tapentadol prolonged release in the elderly and fragile patient: an observational study. Eur Rev Med Pharmacol Sci. 2019; 23 (4 Suppl):45-50.

2. World Health Organization. WHO's Pain Relief Ladder [homepage in Internet]. Genebra: WHO; 2017; [assessed 2017 Feb 9]. Available at: http://www.who.int/cancer/palliative/ painladder/en/.

3. Wade WE, Spruill WJ. Tapentadol hydrochloride: a centrally acting oral analgesic. Clin Ther. 2009;31:2804-18.

4. Vadivelu N, Timchenko A, Huang $Y$, Sinatra R. Tapentadol extended-release for treatment of chronic pain: a review. J Pain Res. 2011;4:211-8.

5. Taylor R, Pergolizzi JV, Raffa RB. Tapentadol extended release for chronic pain patients. Adv Ther. 2013;30:14-27.

6. Butterworth J, Mackey DC, Wasnick J. Morgan and Mikhail's Clinical Anesthesiology. 5th ed. New York: McGraw-Hill Education; 2013.

7. Sanchez Del Aguila MJ, Schenk M, Kern KU, Drost T, Steigerwald I. Practical considerations for the use of tapentadol prolonged release for the management of severe chronic pain. Clin Ther. 2015;37:94-113.

8. Ballantyne JC, Kalso E, Stannard C. WHO analgesic ladder: a good concept gone astray. BMJ. 2016;352:i20.

9. Deeks E. Tapentadol Prolonged Release: A Review in Pain Management. Drugs. 2018;78:1805-1816. 